\title{
O traje de cena como documento
}

\author{
Costume as document
}

\author{
Fausto Viana
}

Fausto Viana

Professor do Departamento de Artes Cênicas da Escola de Comunicação e Artes da Universidade de São Paulo (CAC-ECA-USP).

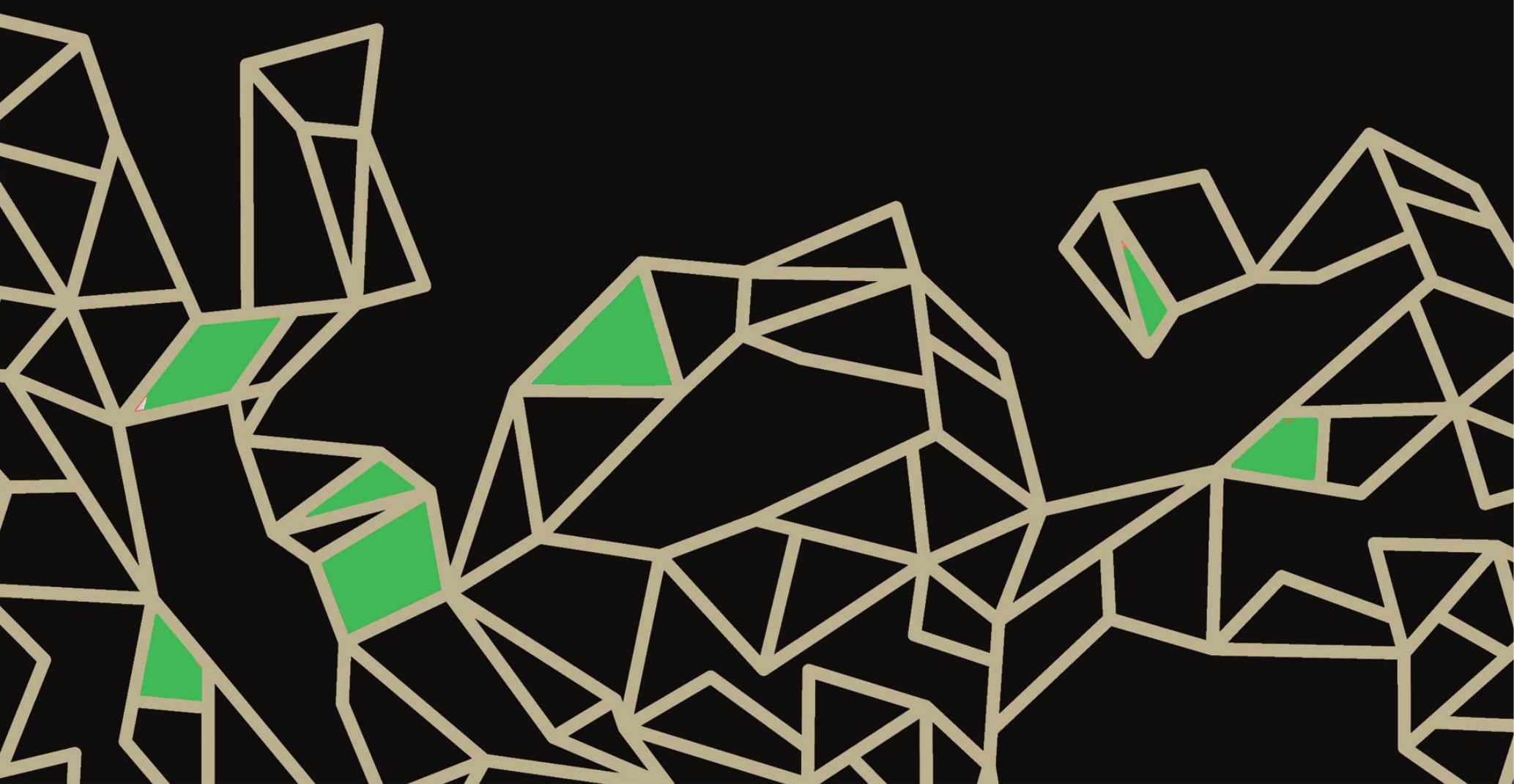




\section{Resumo}

Este artigo busca investigar o traje de cena, ou figurino, como um objeto que faz parte do espetáculo nas suas mais variadas vertentes e que, depois de encerrado o evento, se torna vestígio material. Nessa nova condição, torna-se um documento, como descrevem Le Goff, Rússio e Pavis, e sua análise permite ajudar a entender - não recompor, dada a natureza efêmera dos eventos dos quais participa - o espetáculo do qual fez parte, a partir de características materiais contidas nele (tecidos, formas, cores...) e de outros documentos a ele associados (fotografias, croquis...).

Palavras-chave: Traje de cena, Figurino, Documento.

\section{Abstract}

This article aims to investigate costume, or stage clothes, as an object that is part of a show in its most varied categories and that, after the show is ended, becomes material vestige. Under that new condition, it becomes a document, as described by Le Goff, Rússio and Pavis, and its analysis helps to understand a show in which it took part in - not to rebuild it (due to the ephemeral nature of the events in which it takes part in) -, based on its material characteristics (fabric, forms, shapes) and on other documents associated to it (photographs, sketches...).

Keywords: Costume, Stage clothes, Document.

\section{O que é um documento}

Patrice Pavis (1999), professor de estudos teatrais recentemente aposentado da Universidade de Kent, no Reino Unido, faz uma clara relação do que considera documentação em teatro, apresentando-a da seguinte maneira:

1. Os textos, gravados ou transcritos, que Pavis considera um rastro muito tênue da representação, na medida em que o teatro e a performance são artes difíceis de documentar;

2. Documentos brutos, ou "monumentais", como ele anota. Neste agrupamento, estão os figurinos, a cenografia, os objetos de cena e outros; 
3. Documentos anexos: são fontes pictóricas, arquitetônicas ou lúdicas da representação, que pertencem ao domínio ilimitado da arte e da cultura.

Em 2011, a pesquisadora francesa Béatrice Picon-Vallin, ex-diretora de pesquisa do Centro Nacional de Pesquisa Científica, o CNRS na França, proferiu uma palestra no Teatro Laboratório da Escola de Comunicações e Artes da Universidade de São Paulo (ECA-USP) ${ }^{1}$, em que abordou a possível criação de um museu de teatro na França. "Assim que os espectadores deixam a sala, o espetáculo não existe mais, a não ser na sua memória. Tudo o que se pode fazer é reunir os materiais da preparação e da realização desse espetáculo", ela disse na ocasião, complementando que "em um museu de teatro não se tem a obra, tem-se os restos da obra, os fragmentos, os destroços" (apud VIANA, 2015a, p. 21).

Procurou-se fazer no Quadro 1 uma sistematização da divisão que Picon-Vallin propôs para o material que iria para o museu. Os grifos indicam como o traje de cena e material a ele relacionados estavam presentes nas três etapas de seleção do futuro acervo.

Quadro 1 - Material a ser incorporado a um eventual museu do teatro na França

\begin{tabular}{|l|l|l|}
\hline \multicolumn{1}{|c|}{$\begin{array}{l}\text { MATERIAL PRÉ- } \\
\text {-ESPETÁCULO }\end{array}$} & \multicolumn{1}{|c|}{$\begin{array}{l}\text { MATERIAL DO } \\
\text { ESPETÁCULO }\end{array}$} & \multicolumn{1}{|c|}{$\begin{array}{c}\text { MATERIAL PÓs- } \\
\text {-ESPETÁCULO }\end{array}$} \\
\hline $\begin{array}{l}\text { Desenhos; croquis; } \\
\text { cenários; figurinos; } \\
\text { amostras de tecidos } \\
\text { para os trajes; maquetes } \\
\text { em volume; documentos } \\
\text { escritos; cartas, toda a } \\
\text { correspondência do projeto, } \\
\text { desde sua invenção; a } \\
\text { fotografia; fotografias dos } \\
\text { ensaios; fotos posadas em } \\
\text { cena. }\end{array}$ & $\begin{array}{l}\text { Croquis feitos diante do } \\
\text { espetáculo e do que se via } \\
\text { em cena. Fotos de cena. } \\
\text { Gravações de áudio e vídeo. }\end{array}$ & $\begin{array}{l}\text { Objetos que pertenceram } \\
\text { aos artistas durante as } \\
\text { encenações; os próprios } \\
\text { trajes; os acessórios; a } \\
\text { música (partitura ou } \\
\text { gravação); as máscaras; } \\
\text { as obras eventualmente } \\
\text { escritas sobre o } \\
\text { espetáculo; quadros feitos } \\
\text { a partir do espetáculo, os } \\
\text { retratos de artistas em } \\
\text { diversos meios e formatos. }\end{array}$ \\
\hline
\end{tabular}

Fonte: Elaboração e grifos do autor, a partir da proposta de Picon-Vallin (2011).

1 A transcrição e tradução da palestra foram feitas pela Profa. Dra. Elizabeth Azevedo. 
Jacques Le Goff (1990), historiador francês que também trabalhou no CNRS, explicou que o termo latino documentum tem uma longa trajetória, que deriva de docere (ensinar) e segue até atingir o significado jurídico de "prova", amplamente utilizado no vocabulário legislativo.

O termo latino documentum, derivado de docere "ensinar," evoluiu para o significado de "prova" e é amplamente usado no vocabulário legislativo. É no século XVII que se difunde, na linguagem jurídica francesa, a expressão titres et documents e o sentido moderno de testemunho histórico data apenas do início do século XIX. [...] O documento que, para a escola histórica positivista do fim do século XIX e do início do século $X X$, será o fundamento do fato histórico, ainda que resulte da escolha, de uma decisão do historiador, parece apresentar-se por si mesmo como prova histórica. A sua objetividade parece opor-se à intencionalidade do monumento. Além do mais, afirma-se essencialmente como um testemunho escrito. (Ibid., p. 535, grifos no original)

Waldisa Rússio, museóloga e professora do curso de museologia na Fundação Escola de Sociologia e Política de São Paulo, concordou com o pesquisador francês e acrescentou um dado que é fundamental. "O documento não apenas diz", ela esclareceu, "mas ensina algo de alguém ou alguma coisa; e quem ensina, ensina alguma coisa a alguém" (RÚSSIO apud BRUNO, 2010, p. 205).

Para Rússio, o objeto museal é também um documento: "o fato de um objeto ser um documento, um testemunho autêntico, está ligado com o domínio dos conhecimentos do museu (antropologia, arqueologia, química, etnologia, matemática, etc.), isto é, as perspectivas através das quais são estudados o homem e seu ambiente" (Ibid., p. 125).

O que poderia ser considerado uma restrição de Le Goff, qual seja, o documento ser um testemunho escrito, fica expandido pelos indicativos de Rússio ao tratar objetos como documentos. Para a arquivística, um documento é "toda informação registrada em um suporte material, suscetível de ser utilizada para consulta, estudo, prova e pesquisa, pois comprovam fatos, fenômenos, formas de vida e pensamentos do homem numa determinada época ou lugar" (BRASIL, 1995, p. 11). 
Documento, para o Arquivo Nacional, é uma "unidade de registro de informações, qualquer que seja o suporte ou formato" (Id., 2005, p. 73). Os exemplos citados são: impressos, livros, folhetos, periódicos; filmes, fitas videomagnéticas; em meio eletrônico, em suporte digital, em suportes especiais que não só papel, imagens em movimento...

Não são citados textualmente "trajes" ou "suporte: tecido", como o fazem as coleções museológicas. Mas um bom exemplo complementar é o da Biblioteca Nacional da França (BNF). Parte do material guardado na BNF foi solicitado em 1992 para compor o acervo do Centro Nacional do Traje de Cena (CNCS). Aqui está, diretamente do site do CNCS, a lista de alguns materiais oferecidos pela biblioteca:

A coleção providenciada pela Biblioteca Nacional da França reflete a riqueza e variedade da coleção do seu Departamento de Artes Performáticas. Inclui os trajes da trupe Renaud-Barrault; do Théâtre de l'Atelier sob a direção de Charles Dullin; do Théâtre du Campagnol dirigido por Jean-Claude Penchenat e que se somam aos trajes de Philippe Guillotel para os Jogos Olímpicos de Albertville, dramatizados por Philippe Decouflé, em $1992^{2}$.

A transferência não marcou o fim dos trajes de cena - que nem sempre necessariamente têm suportes têxteis - na BNF. O Thêàtre du Soleil recentemente transferiu seu acervo histórico para a Biblioteca. "Nós começamos a transferir parte dos nossos trajes para a BNF. Alguns trajes de Os átridas já podem ser consultados!"’3. Se o site do Soleil não soar confiável ao leitor, basta checar no site da Biblioteca, pois lá consta exatamente o seguinte: "Fundo Thêàtre du Soleil - direção: Mnouchkine, Ariane (teatro)"'.

Os documentos foram selecionados criteriosamente pelo Soleil e pela BNF, para atender critérios específicos, como propõe Patrice Pavis (1999, p. 108):

O processo de documentação exige uma clara consciência teórica daquilo que o tratamento das informações permitirá coletar e explorar: ele

2 Disponível em: <https://goo.gl/4m1BhR>. Acesso em: 23 set. 2017. Tradução minha.

3 Disponível em: <https://goo.gl/xX1FTd>. Acesso em: 23 set. 2017. Tradução minha.

4 Disponível em: <https://goo.gl/B7Y12G>. Acesso em: 23 set. 2017. Tradução minha. 
depende de todo o processo de pesquisa e do olhar que este baixa sobre o objeto que se está tentando documentar.

Não é o fato de ser um traje de cena que faz com que este seja guardado. A escolha do material deve sempre obedecer a critérios de seleção e a uma política de acervo bem construída.

\section{O traje de cena como objeto/documento}

Susan Pearce (2006), professora de museologia na Universidade de Leicester e especialista em cultura material, na introdução de Interpreting objects and collections discute que todo o material existente em um museu foi, um dia, parte de um processo relacional com seu proprietário, incluindo seu corpo. Waldisa Rússio chama isso de fato museal, "uma relação profunda entre o homem, sujeito conhecedor, e o objeto que é parte da realidade à qual o homem pertence e sobre a qual ele age" (apud VIANA, 2010, p. 86).

O traje de cena, segundo definição prévia do autor deste texto, é "a indumentária das artes cênicas. O termo, mais amplo que traje teatral, pode abranger trajes de teatro, dança, circo, mímica e performance" (VIANA, 2015b, p. 65), que foi complementada posteriormente com "teatro pós-moderno ou pós-dramático, enfim, todo e qualquer evento que contenha cenas ou suas variantes" (VIANA, 2015a, p. 17)

A relação do traje de cena não se dá diretamente apenas com o corpo do performer ou gerando uma relação entre performer e objeto. A relação é muito mais ampla pois envolve os outros artistas de cena. Essa relação se complementa com o trabalho de diversos outros profissionais que compõem a cena e cujo trabalho afeta o traje. Dentre eles, o iluminador: sem luz, não há figurino. Com determinada luz, obtém-se determinado efeito ou cor. $\mathrm{E}$ assim por diante, passando pelo cenógrafo, pelo sonoplasta, pelo maquiador... A grafia da cena, a cenografia, envolve todos nessa arte que em essência é puramente colaborativa.

Há ainda uma relação muito maior: a desse todo interativo com o público, receptor final do trabalho artístico. $O$ traje de cena é apenas uma das partes desse processo e, muitas vezes acidentalmente, é o único elemento que 
atravessa a história das representações teatrais e acaba tornando-se o único testemunho material de uma determinada representação teatral. Com isso, pode se tornar um documento muito importante (VIANA; GIROTTI, 2010).

Para garantir um melhor aprofundamento da investigação sobre um traje de cena, pode-se seguir o roteiro que Pearce (2006) estabeleceu para o estudo de objetos/artefatos. O roteiro seria este:

1. Estudar a história do objeto, sua procedência e maneira de aquisição;

2. Identificar o material de que é feito;

3. Analisar sua construção e ou técnicas construtivas;

4. Ver o design e, por extensão, o designer;

5. Verificar sua função;

6. Identificar o objeto, em descrição fatual, o mais próximo e detalhadamente possível;

7. Avaliar o objeto - julgamento e comparação com outros objetos, não necessariamente para avaliar o valor financeiro da peça;

8. Realizar análise cultural, a relação do artefato com sua cultura;

9. Verificar aspectos destacados da cultura do objeto;

10. Interpretar o objeto, seu significado, através dos valores da cultura do presente.

Há informações prévias sobre o traje; outras que são contidas no objeto e aquelas que são informações complementares a ele.

\section{Informações prévias sobre o traje}

Como um traje chega ao acervo? Escolheram-se aqui três casos diferentes para ilustrar as inúmeras possibilidades de como isso pode acontecer.

Na Figura 1, o traje pertencia ao guarda-roupa da Escola de Arte Dramática (EAD) da ECA-USP, que abriga o Núcleo de Traje de Cena, que recebeu a peça por transferência. Sabe-se que ele foi usado por Alberto Guzik, em 1965, no espetáculo Na Vila da Vitória, de José de Anchieta. A partir dessa informação, pode-se levantar o diretor do espetáculo, o figurinista, a equipe técnica, o 
local de apresentações... O traje foi feito no Brasil por costureiras brasileiras, como entrevistas confirmariam depois.

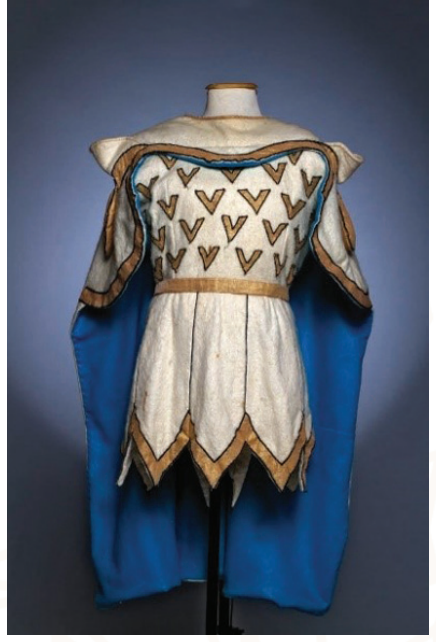

Figura 1 - Traje da personagem Amor de Deus.

Acervo: Núcleo de Traje de Cena. Foto: R. Gutierrez 2015.

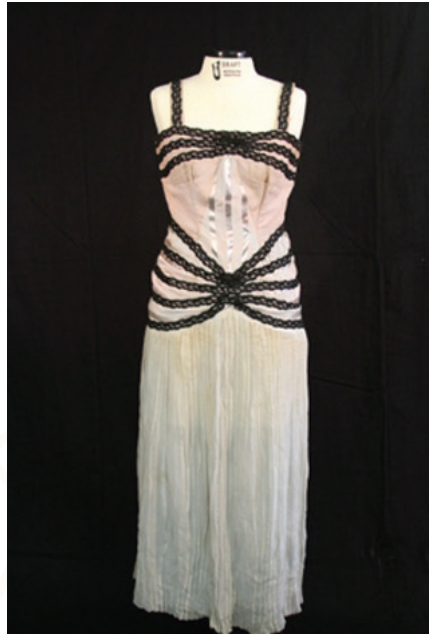

Figura 2 - Traje da ópera Aída.

Acervo: Núcleo de Traje de Cena. Foto: R. Gutierrez, 2015.

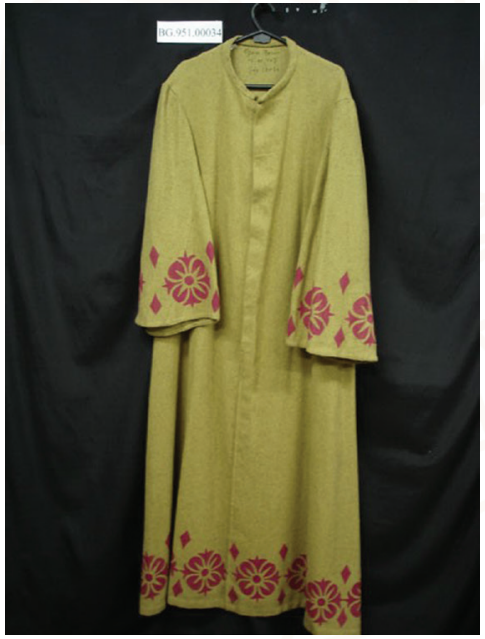

Figura 3 - Traje do espetáculo Boris Godunov.

Acervo: Theatro Municipal de São Paulo. Foto: Fausto Viana, 2015.

O traje da Figura 2 veio em doação para o Núcleo. A sobrinha da soprano Constantina Araújo, Cláudia Ranzinni, fez a doação de uma coleção completa, com histórico detalhado. Destacam-se as seguintes peças: trajes de cena que incluem cinturões, adereços vários de ópera e ópera chinesa, perucas, apliques de cabelo, penas, galões para aplicação em roupas, uma sombrinha chinesa, sapatos, toucas, um diadema, brincos, anéis, saiotes e seis vestidos de cena. O material veio com fotos e detalhes das apresentações, chegando ao requinte de receber-se um molde de traje cortado em folha jornal, com a data do jornal, revelando um modo de produção caseiro/artesanal empregado pela cantora. Percebeu-se também que ela costurava alguns trajes e que sua manutenção não era feita pelos técnicos do teatro, mas sim por ela mesma.

O traje da Figura 3 é da ópera Boris Godunov, produção do Theatro Municipal de São Paulo de 1951. A história dos figurinos desse espetáculo foi encontrada em um documento da negociação dos trajes de um conjunto de diversas óperas, entre elas Boris Godunov. O contrato foi assinado por um representante da Prefeitura de São Paulo e por um intermediador que 
representava uma casa produtora de trajes na Itália. Eram óperas bastante distintas, com produção muito artesanal e bela. Mas tudo leva a crer que era um lote de peças previamente utilizadas, com no mínimo três anos de uso, como avaliou-se na ocasião dos trabalhos de catalogação dos trajes do Theatro Municipal em 2005/2006. O processo de aquisição foi por compra direta.

\section{Informações contidas no traje}

O traje da Figura 1 é feito de feltro creme, com forro do mesmo material, rústico e simples. É um tecido muito barato hoje, bem como nos anos 1960, quando foi feito. Tem aplicações de um tecido de lamê, também barato, preso ao traje por um bordado feito à máquina com linha preta. O processo de confecção é muito simples, como o de muitos trajes que pertenceram ao acervo da EAD-USP. O figurinista não identificado era aluno do curso de cenografia que a escola oferecia no período. Há um detalhe que pode ser considerado escandaloso para a época: é muito curto, como aponta a Figura 4, e usado sem meias compridas por baixo.

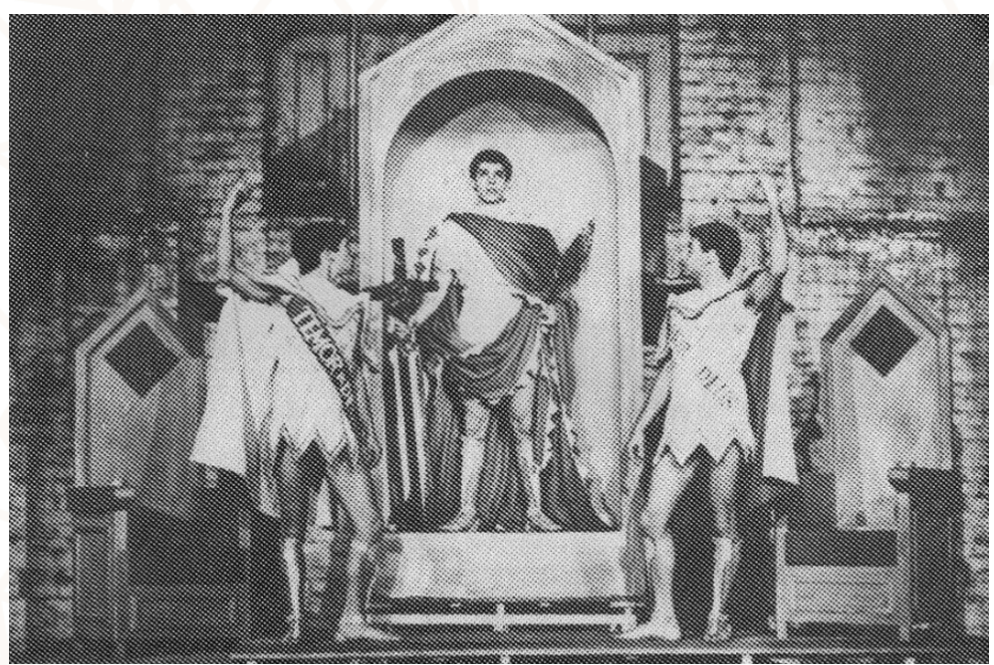

Figura 4 - $\mathrm{O}$ traje da Figura 1, da personagem Amor de Deus, à direita, em cena do espetáculo.

Acervo: EAD-USP. Fotógrafo não identificado, 1965.

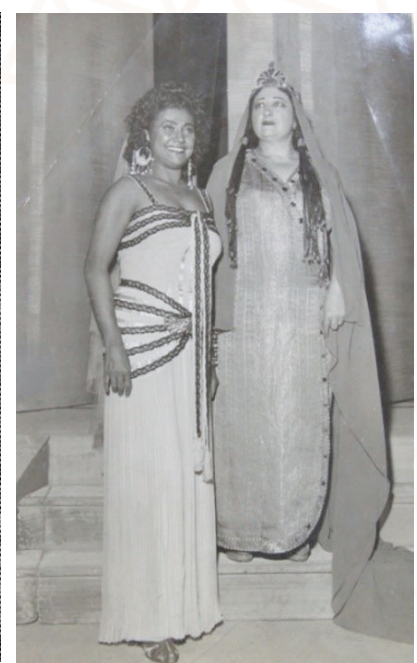

Figura 5 - Traje de Aída, de C. Araújo.

Acervo: Núcleo de Traje de Cena. Fotógrafo não identificado, década de 1950. 
O traje da Figura 2, por sua vez, é de chiffon e de outros tecidos mais refinados. $O$ vestido se encontra com manchas por ter sido guardado dobrado. Foi ajustado ao corpo da cantora, provavelmente confeccionado para ela ou até mesmo por ela, para a ópera Aída, de Verdi, possivelmente no Teatro alla Scala de Milão, na década de 1950. A Figura 5 mostra como os acabamentos pretos fazem contraste com a delicada superfície dos tecidos do corpete e da saia, definindo bem os quadris generosos da cantora, tão em voga no período. Constantina era cantora de repertório e o traje era provavelmente seu, usado nas récitas e nos espetáculos para os quais era contratada, como está registrado no seu caderno de apresentações, que traz ainda o valor recebido por ela em cada apresentação.

O traje da Figura 3, de Boris Godunov, é feito de lã de muito boa qualidade. Destaca-se a pintura feita com estêncil, com tinta avermelhada, que delimita bem um período histórico, mas deixa muito a desejar no quesito contraste. Provavelmente ficou muito chapada com a iluminação, mas não se têm imagens de cena desse espetáculo.

Há outra característica nesse traje: sua tipologia e sua repetição visual em espetáculos. A Figura 6, por exemplo, mostra outro traje da produção de 1951 do Theatro Municipal de São Paulo. A Figura 7 também mostra um Boris Godunov, mas dos anos 1960 e empregado no Teatro Lírico de Equipe, um grupo de cantores amadores que se apresentava em São Paulo. Em comum, tinham muitas vezes o mesmo figurinista. Não é só isso que gera a semeIhança entre os trajes: também as mangas compridas com pele nas extremidades para representar um boiardo, um russo aristocrata.

Há uma expectativa do público de reconhecer as personagens principais e as situações em que estão envolvidas. Personagens mais populares têm figurinos característicos, como Mimi, da ópera La Bohème, que vem sempre com seu vestido xadrez a bordar flores e lantejoulas para sobreviver (Figuras 9, 10 e 11), e Violetta Valéry, a transviada que dá título à ópera La Traviata, que usa sempre um vestido branco na festa em que conhece seu grande amor e pensa em desistir de ser cortesã (Figura 8).

A commedia dell'arte ainda aposta nesses personagens tipos e em seus trajes facilmente reconhecíveis, como o Arlequim nas suas mais diversas versões. A tendência de se usar o mesmo traje para as personagens que se 
repetem é histórica e não é exclusiva do teatro ocidental: o teatro japonês, a Ópera de Pequim e o teatro indiano se valem desse mesmo recurso.

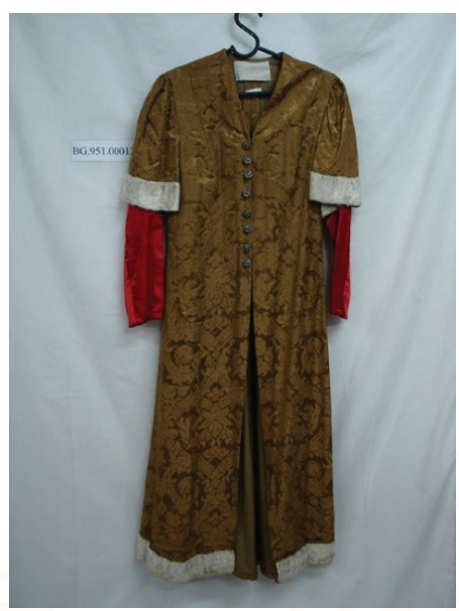

Figura 6 - Um traje de Boris Godunov, produção do Theatro Municipal, 1951.

Acervo: Theatro Municipal de São Paulo. Foto: Fausto Viana, 2006.

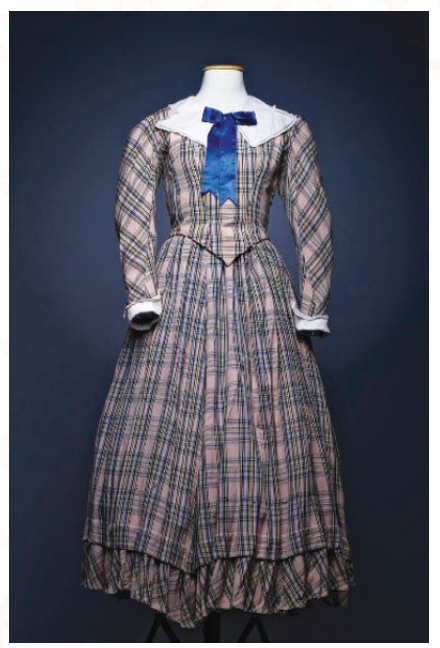

Figura 9 - O traje de Mimi do Teatro Lírico de Equipe, anos 1960. Acervo: Núcleo de Traje de Cena. Foto: R. Gutierrez, 2015.

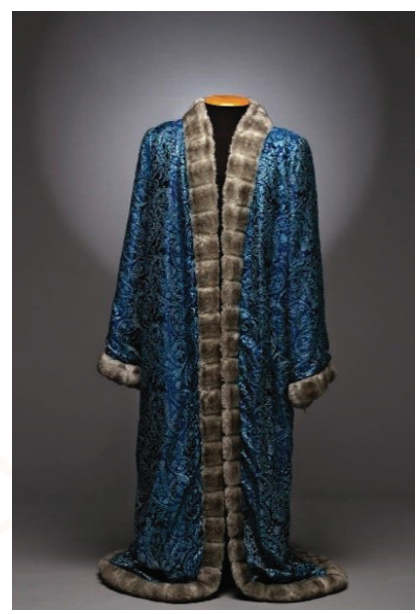

Figura 7 - O traje de Boris Godunov do Teatro Lírico de Equipe, dos anos 1960.

Acervo: Núcleo de Traje de Cena. Foto: R. Gutierrez, 2015.

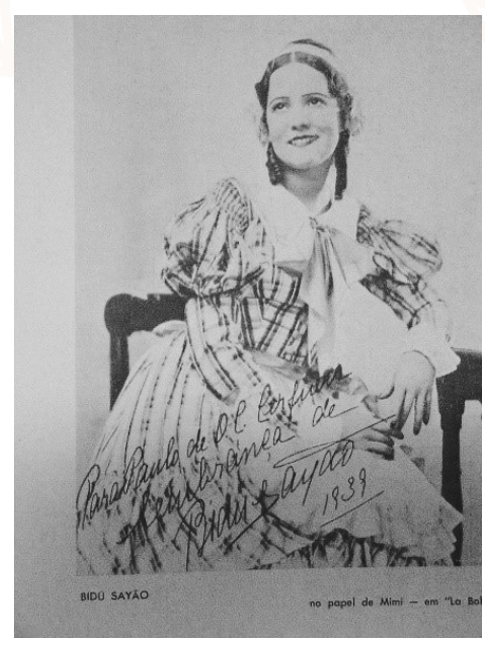

Figura 10 - Bidu Sayão, com traje de Mimi em foto de 1939.

Fonte: Museu do Theatro Municipal de São Paulo, programa da La Bohéme de 1947. Foto: Fausto Viana, 2008.

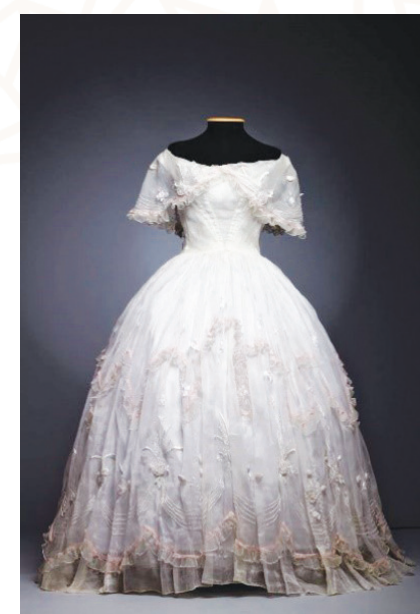

Figura 8 - O traje de Violetta Valéry do Teatro Lírico de Equipe, anos 1970.

Acervo: Núcleo de Traje de Cena. Foto: Ronaldo Gutierrez, 2015.

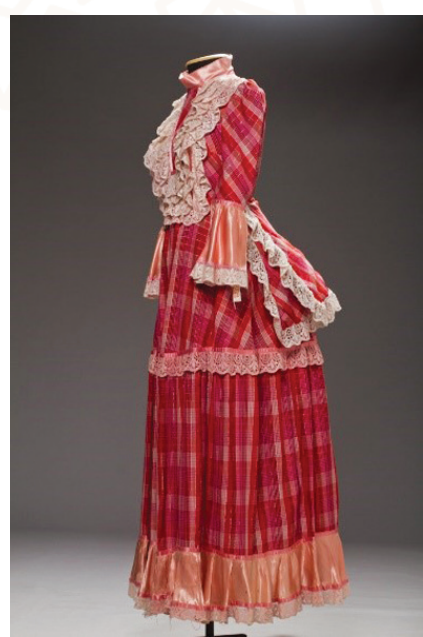

Figura 11 - $O$ traje de Mimi do Teatro São Pedro, de São Paulo, década de 1960.

Acervo: Núcleo de Traje de Cena. Foto: R. Gutierrez, 2015. 
O traje enquanto objeto ainda traz outras características, e cada uma delas oferece uma interpretação. As mais fáceis são cor (que influencia de imediato a percepção do público, tanto sobre a personagem como sobre a situação), forma (a maneira e o formato como o traje vai ser cortado), volume (espaço a ser ocupado pelo traje), textura (fundamental para interagir com outros tecidos e com a luz), movimento (que vai impregnar o olhar do espectador, que o segue) e origem (no sentido de origem cultural, como um quimono japonês).

Outros itens podem ser considerados: sonoridade (a saia da escrava Mammy, que se movimenta por baixo do traje externo, promovendo um farfaIhar em ...E o vento levou, ou mesmo os guizos de um bobo da corte) e aroma (este para trajes muito próximos ao espectador, que poderá sentir o aroma que exalam).

O traje traz também outras informações sobre sua execução ou sobre o modo de produção do grupo ou companhia do qual faz parte. As etiquetas são boas indicadoras. Na Figura 12, alguém escreveu com caneta azul no traje a seguinte informação: "Leandro (Conselheiro). Tingir de azul e fazer gola de padre (tirar do punho)".

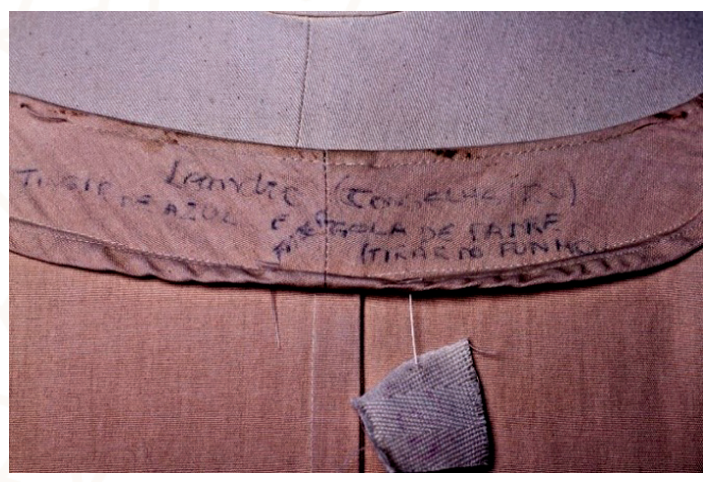

Figura 12 - A gola de um traje, com anotações do figurinista.

Acervo: Núcleo de Traje de Cena. Foto: R. Gutierrez, 2015.

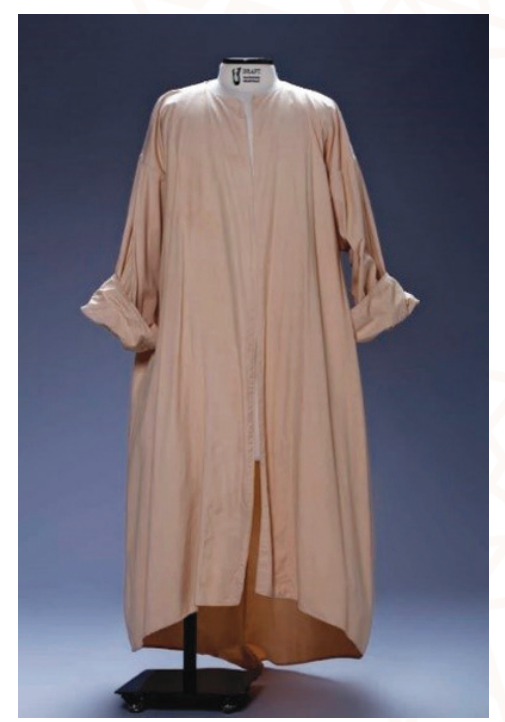

Figura 13 - O traje inteiro onde estão as anotações do figurinista.

Acervo: Núcleo de Traje de Cena. Foto: R. Gutierrez, 2015. 
A natureza do traje de cena é reciclável. A peça em questão, no entanto, escapou do seu destino para trazer informações sobre o modo de produção de determinado grupo. Naquele coletivo, reciclam-se, cortam-se, alteram-se peças. Na Comédie-Française isso é mais raro, mas não quer necessariamente dizer que seja uma questão de aporte financeiro maior ou menor para a produção de figurinos. Tem muito a ver com política do grupo - de criar e guardar acervo, histórico ou não.

As etiquetas trazem informações muito distintas e contam sobre modos de produção de um grupo: se há uma etiqueta de alfaiate, ou de uma butique; se pertenceu a uma casa teatral e de aluguel ou não.

Na Figura 14, há uma etiqueta escura onde se lê: “Casa D’arte G. Ardovino. Roma. Tel.760055. Piazza, Galeria 7". Na Figura 15, lê-se: "Teatro Municipal de São Paulo. Ópera Tosca, personagem Scapino, ator: Luciano, ano 1982." A Figura 16 traz três etiquetas, e em uma delas lê-se "Societá anônima Costumi DArte Milano".

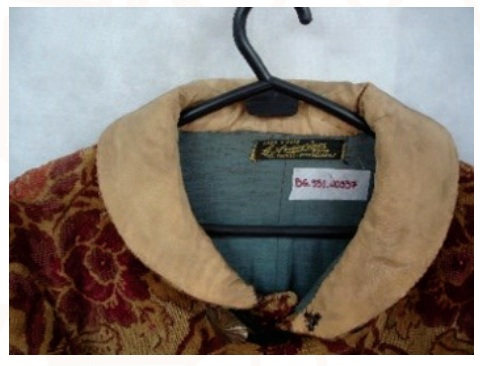

Figura 14 - Traje de Boris Godunov, 1951.

Acervo: Theatro Municipal de São Paulo. Foto: Fausto Viana, 2006.

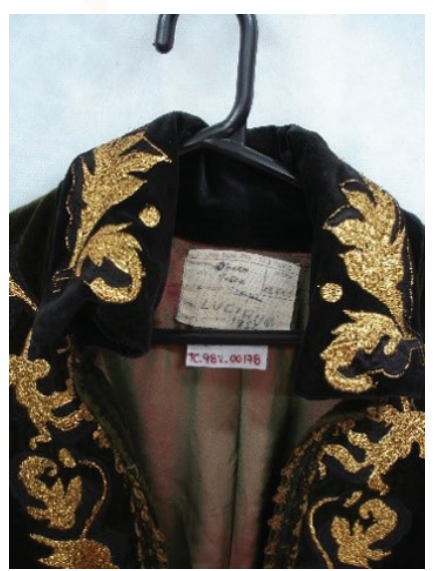

Figura 15 - Traje de Scapino, na ópera Tosca, de 1982.

Acervo: Theatro Municipal de São Paulo. Foto: Fausto Viana, 2006.

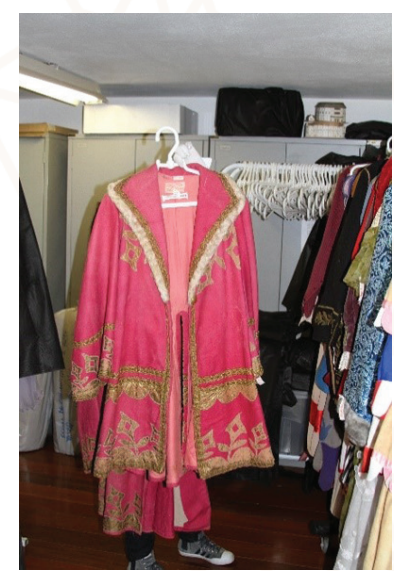

Figura 16 - Uma casaca de lã cor-de-rosa, italiana.

Acervo: Núcleo de Traje de Cena. Foto: Fausto Viana, 2015.

Além de todas as informações já vistas, pode-se verificar a qualidade de execução, se são roupas caras, finas, básicas, improvisadas; e também 
verificar se o material empregado nelas é tradicional ou inovador, ou até mesmo nunca explorado antes.

Outro recurso bastante frequente nos trajes de cena são as trucagens. É o caso da estrutura do traje do "homem mais forte do mundo", no circo, em que se convida dois grupos de homens, um para cada lado do personagem, de forma que ele vá vencer a disputa do cabo de guerra. Há um esquema de cordas que passa por dentro do traje, dando a impressão de que quem está puxando a corda é a pessoa que o veste, mas na verdade não: são os dois grupos, um de cada lado, que estão puxando a corda e se digladiando.

As Figuras 17 e 18 mostram a trucagem em uma casaca do Teatro Lírico de Equipe. De forma imperceptível, costurou-se um coldre na própria roupa. $\mathrm{O}$ objeto "conta" que provavelmente o ator precisava sacar a arma rapidamente, e que colocá-la na altura do seu peito - lugar incomum - resolveria bem o problema da cena.
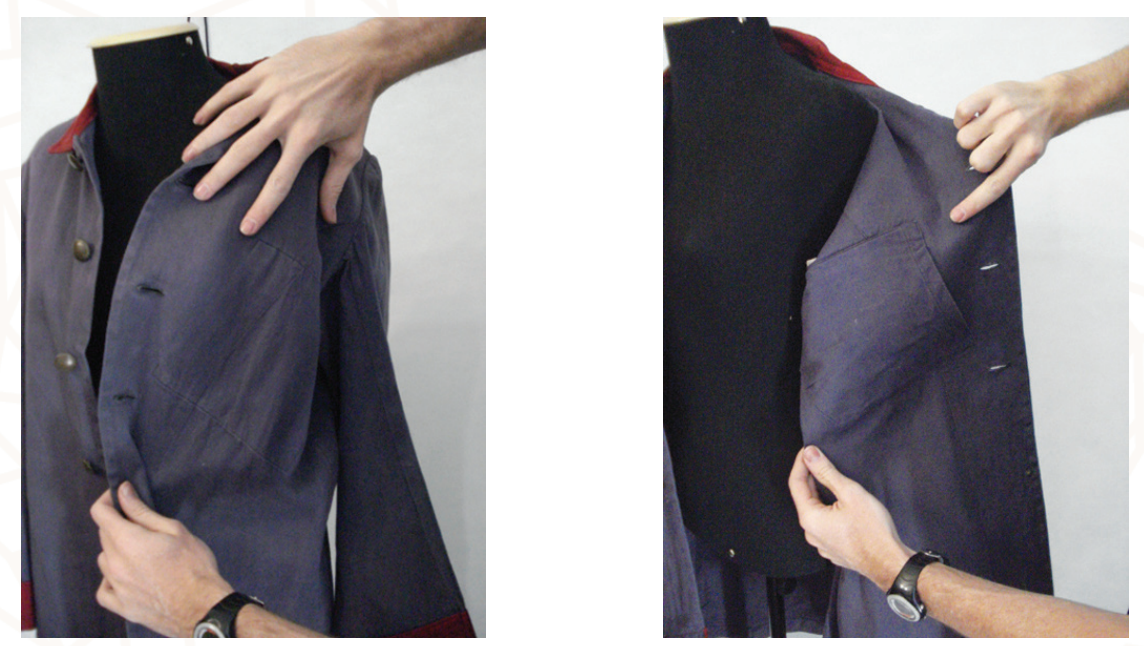

Figuras 17 e 18 - Um espaço para guardar a arma na altura do peito. Traje do Teatro Lírico de Equipe.

Acervo: Núcleo Traje de Cena. Foto: Fausto Viana, 2014.

Finalmente, deve-se sempre verificar quem é o designer e o que faz com que aquele traje tenha características tão especiais. Apresenta-se aqui dois exemplos muito significativos: Campello Neto e Gabriel Villela.

Os trajes das Figuras 19 e 20 são muito reveladores da capacidade criativa de Campello Neto, um figurinista que estudou em Roma e era admirador confesso de Luchino Visconti. 


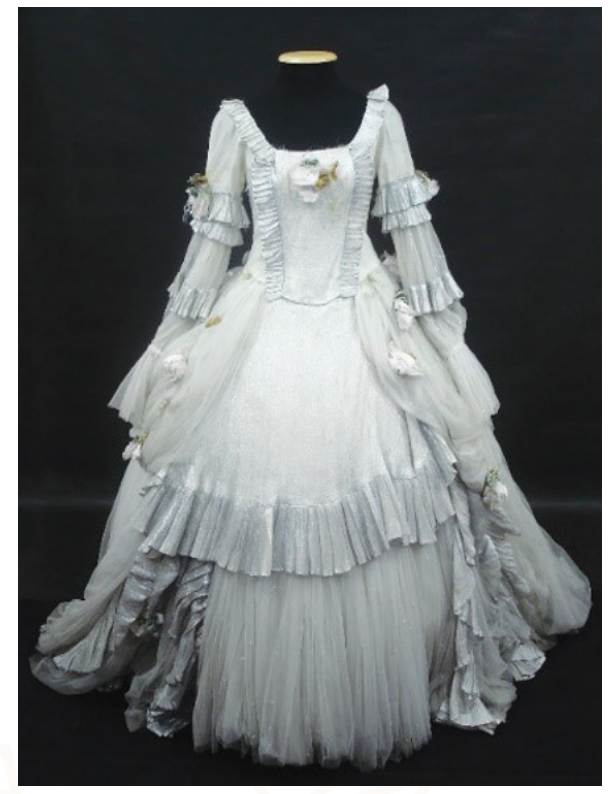

Figura 19 - Traje de Cosi Fan Tutte.

Acervo: Theatro Municipal de São Paulo. Foto: Fausto Viana, 2006.

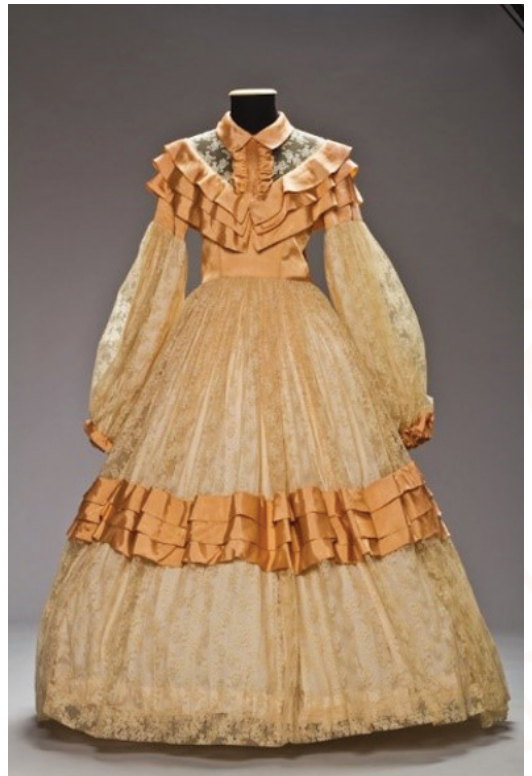

Figura 20 - Traje de Não se brinca com o amor.

Acervo: Núcleo de Traje de Cena. Foto: Ronaldo Gutierrez, 2015.

Campello Neto incorporou em seus trajes a elegância que lhe era peculiar. Buscou sempre materiais alternativos, como na ópera Così Fan Tutte, no Theatro Municipal de São Paulo, quando empregou no traje da Figura 19 apenas lamê barato e tule branco e, no vestido da Figura 20, rendão de cortina, para a peça Não se brinca com o amor. Sendo ele conhecedor dos efeitos de teatro, a luz foi determinante em seu trabalho requintado, que buscava volumes e formas expressivos.

Gabriel Villela, por sua vez, é um diretor que assume em seus espetáculos a função de figurinista e que por meio dos bordados, dos teares mineiros e da mistura de elementos eleva o traje a um novo patamar de beleza e contribuição ao trabalho do ator. Isso se exemplifica na Figura 21, de 0 soldadinho e a bailarina, e na Figura 22, de $A$ tempestade, que trazem trajes criados por Villela com imaginação, mas, acima de tudo, com artesania, com cuidado infinito nos pequenos itens e nos detalhes. 


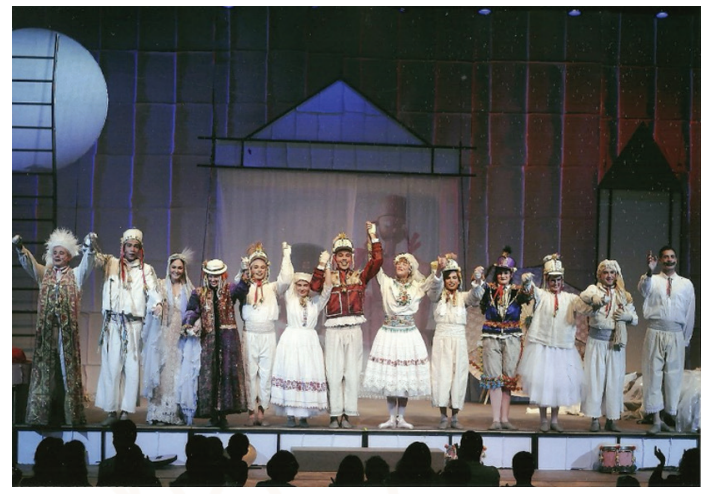

Figura 21 - O soldadinho e a bailarina, 2010.

Foto: Divulgação.

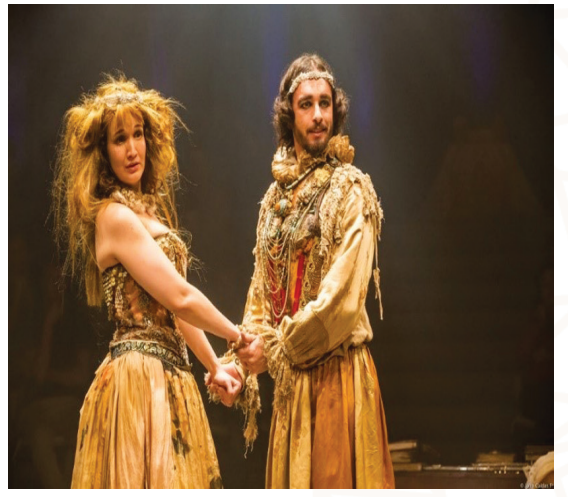

Figura 22 - A tempestade, 2016.

Foto: Divulgação.

\section{Informações complementares ao traje: outras fontes documentais}

São muitos os exemplos que podem auxiliar a complementar o estudo dos trajes de cena. Adereços, como os de Constantina Araújo (Figuras 23 e 24); aquarelas; caricaturas ou charges; croquis (Figura 25); desenhos; anúncios de jornal; desenhos de estátuas e estátuas em si; livros e álbuns; miniaturas; pinturas em vasos; litogravuras; manuscritos; tapeçarias e tecidos; sedas; programas do espetáculo (Figuras 26 e 27) e fotografias.

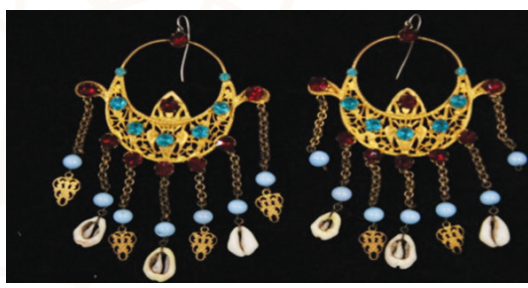

Figura 23 - Par de brincos de Aída, os mesmos que Constantina Araújo usa na Figura 5.

Fonte: Núcleo de Traje de Cena. Foto: Ronaldo Gutierrez, 2015.

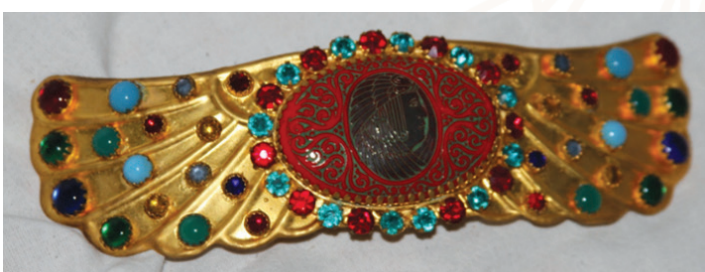

Figura 24 - Fivela decorativa de Aída, usada na Figura 5.

Fonte: Núcleo de Traje de Cena. Foto: Ronaldo Gutierrez, 2015.

As entrevistas em que se falem dos trajes com profissionais do figurino ou com o pessoal envolvido no espetáculo são uma fonte eficaz, mesmo que não tenham imagens, pois ajudam a dirimir dúvidas. Atualmente, existem 
novas fontes documentais: sites da internet, de museus, de pesquisadores, de teatros e companhias.

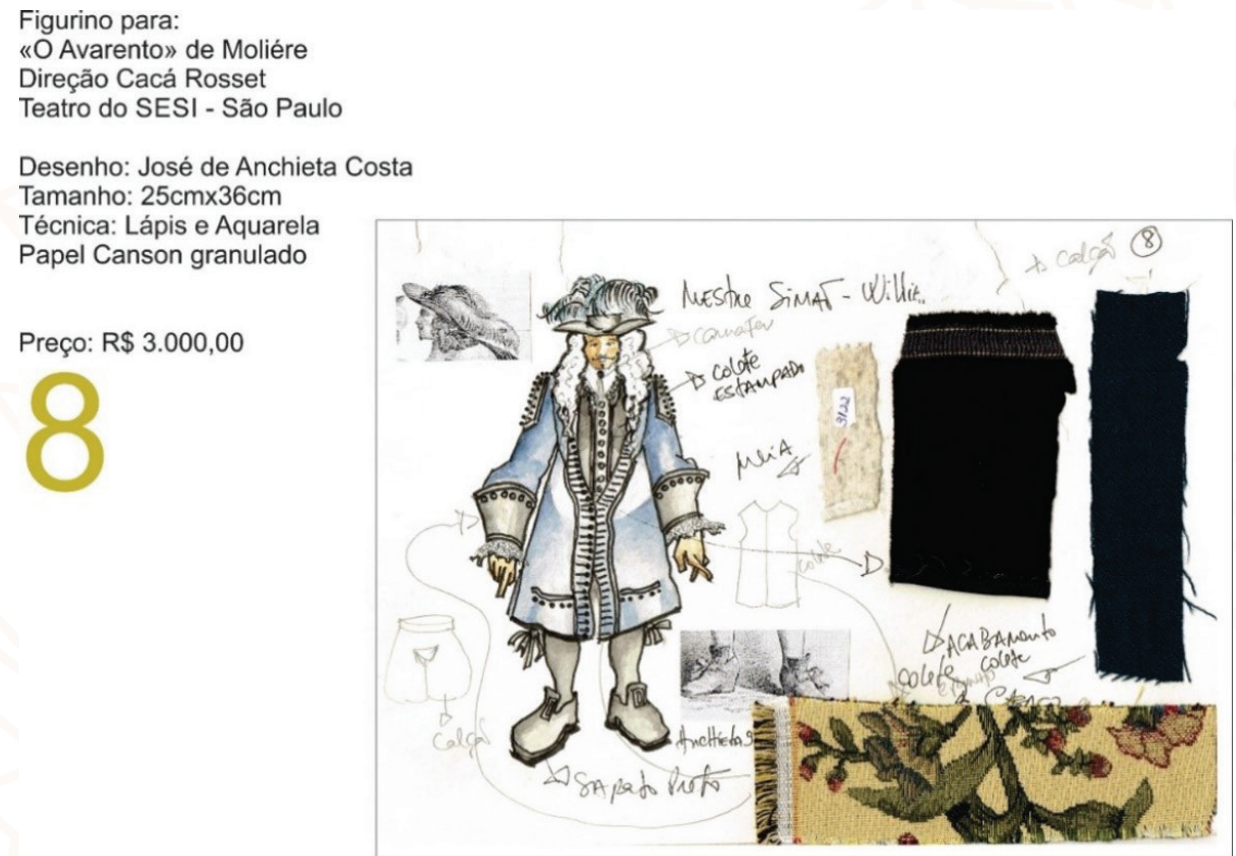

Figura 25 - Croqui de J. de Anchieta para o espetáculo $O$ avarento, com direção de Cacá Rosset, 1998.

Fonte: José de Anchieta.

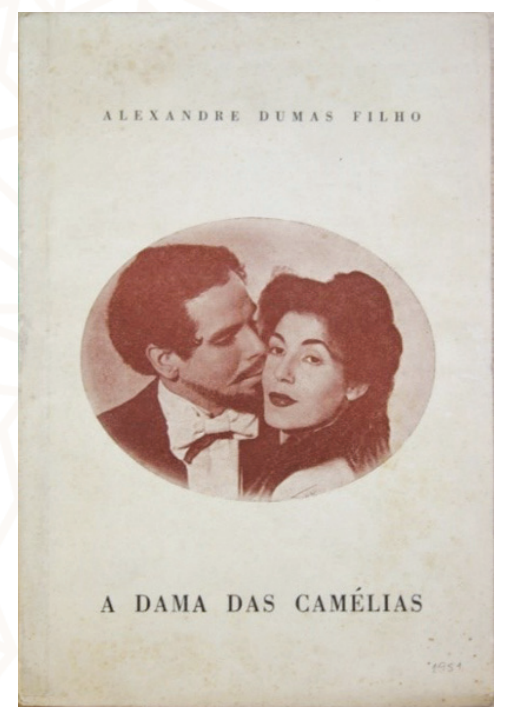

Figuras 26 - O programa gratuito de $A$ dama das camélias, do Teatro Brasileiro de Comédia, 1951.

Fonte: Arquivo do Estado de São Paulo.

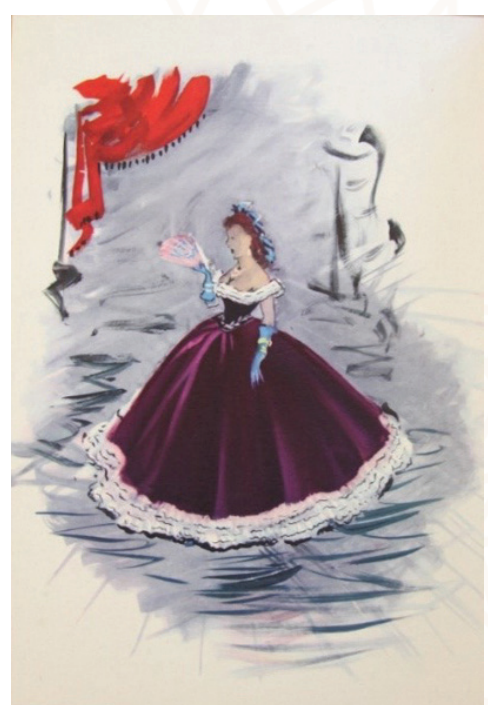

Figuras 27 - $O$ croqui de Aldo Calvo de um dos figurinos, incluído no programa de luxo, que era vendido em 1951. Fonte: Acervo Fausto Viana. 
No entanto, os trajes em si, as roupas ou adereços, são a melhor fonte de pesquisa, quando é possível conservá-los.

No caso do croqui escolhido na Figura 25, do cenógrafo José de Anchieta, a complementação de informações é preciosa. Ele escreve que o traje é para Mestre Simão, criado pelo ator William Amaral. O croqui traz amostras de tecido, bem como cor dos sapatos, material do colete e detalhamento do chapéu. Naturalmente, vale conferir no programa e nas fotografias se tudo aconteceu como planejado, já que não é raro os planos mudarem no meio da jornada.

Todos os documentos são significativos, mas encontrar alguns específicos é um prazer imenso. Por exemplo, a Figura 28 traz uma lista dos bens constantes no Teatro São José, em São Paulo, no ano de 1847.

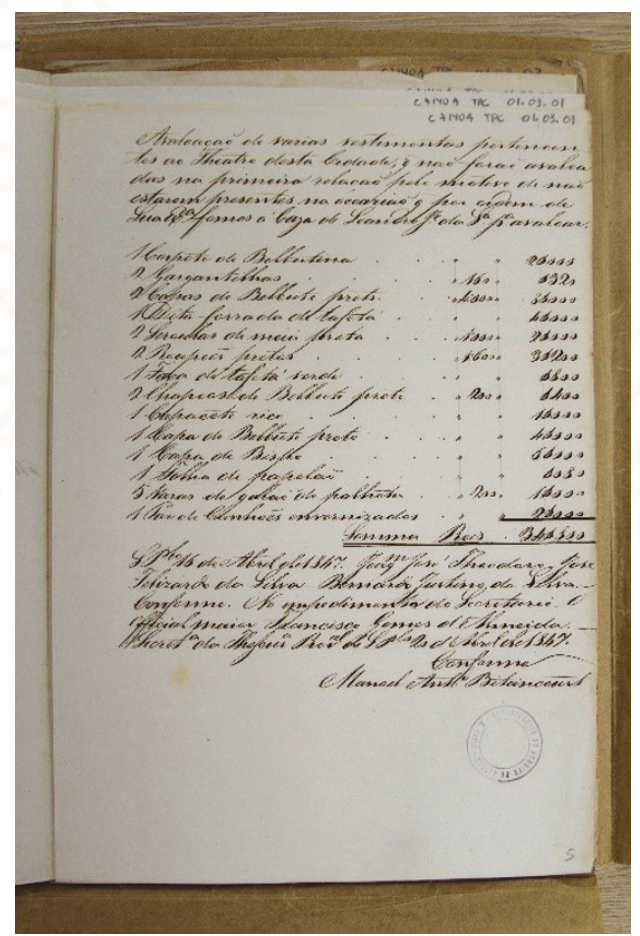

Figura 28 - A lista constante do Dossiê do Teatro São José ${ }^{5}$, de 1847.

Acervo: Arquivo do Estado. Foto: Fausto Viana.

5 Avaliação de várias vestimentas pertencentes ao Teatro desta cidade, que não foram avaliadas na primeira relação pelo motivo de não estarem presentes na ocasião em que por ordem de sua excelência fomos a casa de Leandro [...] da Silva para avaliar. 1 corpete de belbutina / 2 gargantilhas / 2 capas de belbute preto/ 1 dita forrada de tafetá / [...] / 2 roupões pretos / [...] / 1 capacete rico / [...] / 1 capa de Bispo / [...] (20 de abril de 1847 Manoel Antonio Bittencourt). 


\section{Apontamentos finais}

Béatrice Picon-Vallin, na palestra que ofereceu no Departamento de Artes Cênicas da ECA-USP, disse claramente que juntar os materiais que compunham o espetáculo, dentre eles os trajes de cena, não "vai fazer o espetáculo reviver" (apud VIANA 2015a, p. 20) pois, como visto, o teatro é uma arte efêmera. Ainda que não haja um museu de teatro na França, para Picon-Vallin, seu país está um passo adiante em relação ao Brasil, porque a preocupação da pesquisadora é em como exibir esse material, uma vez reunido - ela fez questão de frisar que o material, os diferentes acervos de teatro, já foram recolhidos e estão espalhados pela França. No caso brasileiro, não se começou ainda a fazer essa recolha - não em nível significativo, nacional.

O traje de cena, como visto, é potente instrumento de pesquisa, que tem seu status de documento facilmente reconhecido sob diversos pontos de vista: da história, da arquivística e da museologia. Basicamente, o que o artigo descreveu são atributos materiais do traje de cena e os critérios para avaliá-lo.

Há outros critérios não materiais que envolvem a percepção do espectador a partir do trabalho dos artistas envolvidos. São valores menos palpáveis, subjetivos, mas determinantes do ponto de vista do significado que adquirem. Há critérios estéticos que também são subjetivos e podem cair facilmente no caso de "gosto ou não gosto" - o que pouco interessa para uma abordagem científica do traje. No entanto, vale ressaltar que o trabalho artístico deve se desenvolver em harmonia, para o bem do espetáculo como um todo e da sua recepção pelo público.

O traje de cena é um elo visual forte entre palco e plateia. Oferece suporte criativo para o ator/performer. A possibilidade de ver esses trajes, de imaginar o que os atores ou performers sentiam no momento em que o vestiam, é a chave para entender como uma coleção de trajes e até mesmo como um museu de teatro deveriam funcionar. Picon-Vallin (apud VIANA 2015a) disse que muitas pessoas insistiam para que o museu de teatro na França fosse virtual. Mas, segundo a pesquisadora, ver os trajes, bem como participar, ainda que indiretamente, do processo de se entrar em cena, era uma emoção insubstituível, e foi "assim que encerramos a discussão, pensando 
em como combinar estes 'restos' com todas as possibilidades oferecidas pela tecnologia digital e a internet hoje em dia" (Ibid.).

Em julho de 2017, o autor deste artigo apresentou em São Paulo, no seminário da Federação Internacional para Pesquisa Teatral (IFTR, na sigla em inglês), uma pesquisa sobre cenografia e figurinos criados por Jean-Baptiste Debret no século XIX. Quando foi dito que no Brasil não havia material de cena do século XIX, ou que havia muito pouco material, dadas as condições climáticas, as dificuldades de conservação e outros fatores, Mechele Leon, da Universidade do Kansas, e coordenadora da Comissão de Historiografia, na qual o trabalho foi apresentado, fez um questionamento que parece adequado para encerrar esta breve reflexão: não temos arquivos por quê? A quem não interessa que não existam arquivos?

Certamente, a discussão e a reflexão não deverão ser apenas sobre trajes de cena.

\section{Referências bibliográficas}

BRASIL. Arquivo Nacional. Gestão de documentos: conceitos e procedimentos básicos. Rio de Janeiro: Arquivo Nacional, 1995.

Arquivo Nacional. Dicionário brasileiro de terminologia arquivística.

Rio de Janeiro: Arquivo Nacional, 2005. Disponível em: <https://goo.gl/ZddUMj>. Acesso em: 31 out. 2017.

BRUNO, M. C. O. (Coord.). Waldisa Rússio Camargo Guarnieri: textos e contextos de uma trajetória profissional. São Paulo: Pinacoteca; ICOM, 2010. v. 1.

LE GOFF, J. História e memória. Campinas: Editora da Unicamp, 1990.

PAVIS, P. Dicionário de teatro. São Paulo: Perspectiva, 1999.

PEARCE, S. M. Interpreting objects and collections. London: Routledge, 2006.

VIANA, F. Elaboração e viabilidade de um museu de teatro na cidade de São Paulo. 2010. 408 f. Tese (Doutorado em Museologia) - Universidade Lusófona de Humanidades e Tecnologias, Lisboa, 2010.

O traje de cena como documento. São Paulo: Estação das Letras e Cores, 2015a.

Para vestir a cena contemporânea. São Paulo: Estação das Letras e Cores, 2015b.

VIANA, F.; GIROTTI, M. O figurino dos amadores: dos filodramáticos ao Teatro Lírico de Equipe. In: COLÓQUIO DE MODA, 6., 2010, São Paulo. Anais... São 
Paulo: Abepem; Unesp, 2010. Disponível em: <https://goo.gl/A3Cn2s>. Acesso em: 30 out. 2017.

Recebido em 30/09/2017 Aprovado em 21/10/2017

Publicado em 26/12/2017 